http://jmscr.igmpublication.org/home/

ISSN (e)-2347-176x ISSN (p) 2455-0450

crossref DOI: https://dx.doi.org/10.18535/jmscr/v10i1.06

Journal Of Medical Science And Clinical Research

IGM Publication

An Official Publication of IGM Publication

\title{
Single Roots in Deciduous Mandibular First Molars; a rare bilateral occurrence, unveiling morphological diversities
}

\author{
Authors \\ Dr Fathima $\mathbf{S}^{1^{*}}$, Dr Rita Zarina $\mathbf{A}^{2}$, Dr Digesh Balachandran ${ }^{3}$, Dr Jaziya $\mathbf{Z}^{4}$ \\ ${ }^{1}$ Postgraduate Student- Department of Pediatric \& Preventive Dentistry, Government Dental College, \\ Thiruvnanthapuram \\ ${ }^{2}$ Professor \& Head-Department of Pediatric\& Preventive Dentistry, Government Dental College, \\ Thiruvnanthapuram \\ ${ }^{3}$ Assistant Professor-Department of Pediatric\& Preventive Dentistry, Government Dental College, \\ Thiruvnanthapuram \\ ${ }^{4}$ Postgraduate Student- Department of Pediatric\& Preventive Dentistry, Government Dental College, \\ Thiruvnanthapuram \\ *Corresponding Author
}

Dr Fathima $S$

\begin{abstract}
Familiarity with the diversity of root canal systems dictates the parameters that can affect the prognosis of root canal therapy. Variations in root morphology are rather common occurrences in permanent molars, whereas it is relatively rare in deciduous molars. A usual variation exhibited by deciduous molars is the occurrence of extra roots. The incidence of a deciduous first molar being single-rooted is a scarce finding, especially when occurring bilaterally and with normal occlusal anatomy. This article reports such a rare variation and its successful endodontic treatment.
\end{abstract}

Keywords: single-rooted deciduous molar, endodontic treatment.

\section{Introduction}

The general anatomical configuration of deciduous mandibular molars is two rooted with amesial and adistal root, and commonly with two mesial and one distal root canals. Grewal and Gupta studied root canal configuration in thirty deciduous mandibular first molars and found that $100 \%$ of the specimens had two canals in the mesial root, whereas the distal root had two canals in53.33\% and a single canal in $46.67 \%$ of the specimens. ${ }^{1}$ Deciduous mandibular first molars with single roots and single root canals are rarely reported.
According to Vertucci, root canals are classified into eight main categories. ${ }^{2}$ Class I is single root with single canal and single apical foramen, which is a rare finding in molars. ${ }^{3}$ This article reports such a finding bilaterally in deciduous mandibular first molars of a female child.

Factors leading to developmental abnormalities can either be metabolic or genetic such as inheritance and mutations, as well as environmental factors of physical, chemical and biological natures. It is also possible that some of these anomalies are caused by a combination of both genetic and environmental factors. ${ }^{4}$ 
Complexity of root formation and tooth eruption limits genetic and biochemical information about root genesis. ${ }^{5}$ Only a handful of genes have been described in relation to root formation. ${ }^{6}$ The unique role of $\mathrm{Nfic}$ (nuclear factor I C; a transcriptional factor) in controlling the root but not the crown formation, points to a new concept of different control mechanisms for crown and root. $^{7}$ Literature on etiology of single-rooted molars, suggests a failure in invagination of the Hertwig's epithelial root sheath (HERS), resulting in dysmorphological roots. ${ }^{6}$ However, genetic expression and signalling pathways for the occurrence of single-rooted molars have to be studied further.

\section{Case Report}

A 5 year old female patient witha painful lower right back tooth was referred to Department of Paediatric and Preventive Dentistry, Governmental Dental College Thiruvananthapuram. The child was already under a prescription of antibiotics and analgesics for the complaint. She was otherwise healthy with no relevant medical conditions and having normal milestones of development.

Intraoral examination revealed deciduous dentition with normal occlusal anatomy (figures-1, 2) and a mesial step molar relation. The deciduous mandibular right first molar had a deep carious lesion (figure- 2).

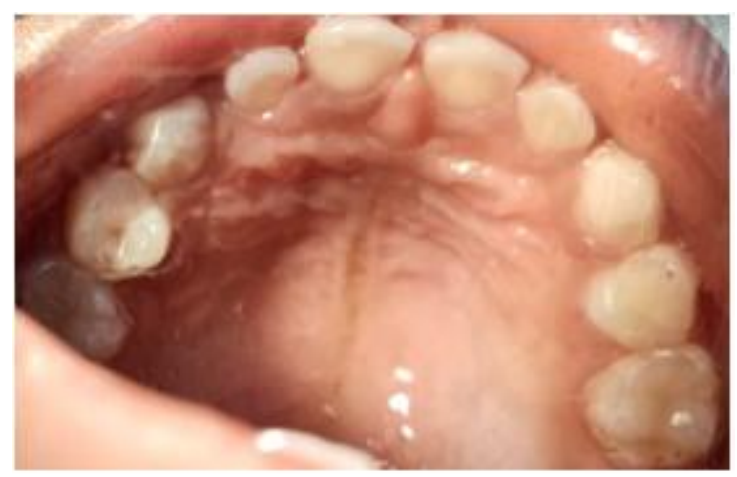

Figure-1; maxillary deciduous dentition

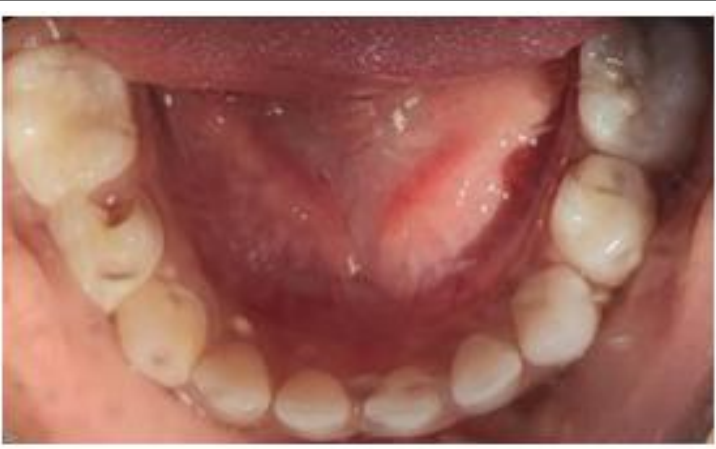

Figure-2; mandibular deciduous dentition, carious 84

Intraoral periapical radiograph (figure-3) of thedeciduous mandibular rightfirst molar was suggestive of pulpal involvement due to the carious lesion and revealed aVertucci's class I type single-rooted tooth(single root with single canaland single apical foamen).There was also notable periradicular radiolucency around its single root. An orthopantomogram revealed single-rooted deciduous mandibular first molars present bilaterally in the patient (figure-4).

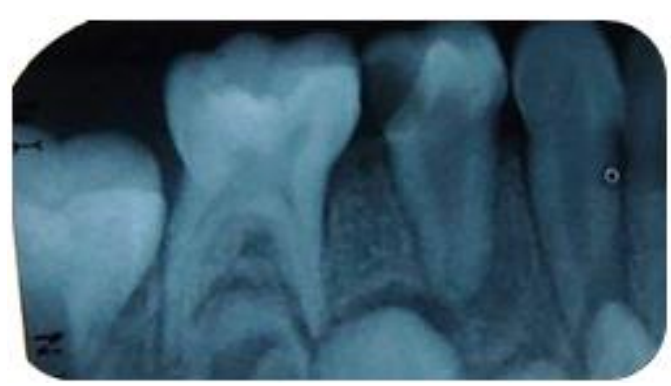

Figure-3; preoperative IOPA showing Vertucci's class I type single-rooted 84 with pulpal involvement

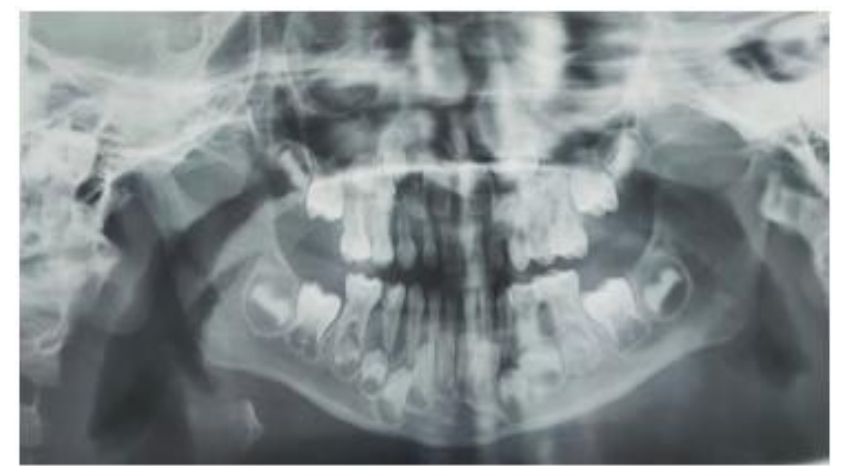

Figure-4; panoramic radiograph showing singlerooted 74 and 84 
Endodontic treatment of the deciduous mandibular right first molar was planned and was carried out with hand instruments. The tooth was obturated with injectable obturating material (vitapex), followed by a coronal restoration with a stainless steel crown (figure-5). Postoperative radiograph revealed satisfactory obturation of the canal (figure-6).

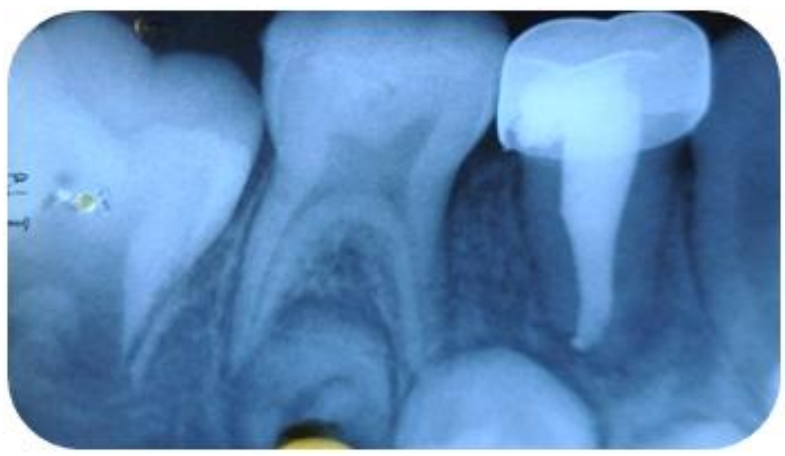

Figure-5; stainless steel crown restored 84

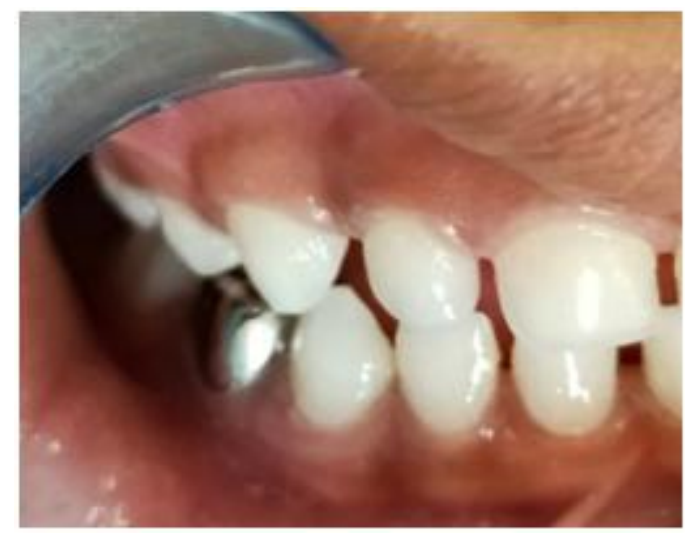

Figure-6; postoperative IOPA showing satisfactory obturation.

The follow up IOPA showed a reduction in the periradicular radiolucency, indicative of a successful endodontic treatment. The patient remains asymptomatic and is under normal periodic dental check-up. The endodontically treated single-rooted deciduous molar as well as the non-carious single-rooted deciduous molar of the contralateral side would be monitored for their uneventful resorption and normal eruption their successors.

\section{Discussion}

An in-depth analysis of multiple morphologic dental anomalies was first reported by Robbins and Keene in 1964, they suggested that single pyramidal shaped roots in molars were inherited as an autosomal dominant condition. ${ }^{8}$ Ackerman reported a kindred with root formation anomalies and described a 10 year-old boy with single conical rootsin all deciduous molars. ${ }^{9}$ They discussed about a group of dental and other abnormalities that occurred in three generations of a family of Scottish-English and German descent. These abnormalities included skin manifestations such as a lack of the 'cupids bow' and thickening of the philtrum, syndactyly of the fingers, and juvenile type glaucoma. ${ }^{9}$

Holan et al. in 1991 reported single-rooted primary and permanent molars and multiple hypodontia in two siblings with autosomal recessive pattern of inheritance. ${ }^{10}$ Manoj Kumar et al.2010 reported a case of single-rooted primary and permanent molars associated with oligodontia in an 11 year old boy. ${ }^{11}$ Ganesh et al. in 2012 reported a case of bilateral single-rooted primary mandibular first molars. ${ }^{6}$ Saxena et al in 2014 reported bilateral single-rooted permanent maxillary first molars. ${ }^{12}$

Morphological dental anomalies are relatively common in the world and many occur in individuals with systemic conditions or syndromes, but the occurrence of a single-rooted deciduous mandibular first molars bilaterally, is extremely rare. Most of these anomalies are related with genetics and environmental factors. The occlusal anatomy in this case was similar to that of any normal deciduous mandibular first molar. Genetic basis could not be assessed due to the non-availability of the dental recordings of the family. However, the possibility of similar dental anomalies running in the family cannot be ruled out.

For many decades, root morphology and root canal anatomy has been the subject of numerous experimental and clinical reports related to endodontics, and is clear that they vary greatly between populations, within populations and even within the same individual. Iatrogenic errors can be minimized with the knowledge of the general 
location and dimension of the pulp chamber. ${ }^{13}$ Endodontic techniques also could be modified suitably to adapt with individual variations of the root morphology and canal anatomy. There is no reported literature regarding any kind of impaction, structural anomalies or delay in eruption of successors of such teeth. However, it would be ideal that the resorption of pulpectomized single-rooted deciduous molaris especially monitored, due to the difference in root morphology and canal anatomy of the pulpectomized tooth, and also due to succedaneous tooth not being positioned in the furcation, in such cases.

Single-rooted deciduous mandibular molar teeth are rare incidences and even rarer when present bilaterally. Its documentation will aid in providing collective data for research and give further insights into its prevalence and the factors associated with development and management of such variations.

\section{Source of Support and Acknowledgement: Nil}

\section{Reference}

1. Gupta D, Gerwal N. Root canal configuration of deciduous mandibular first molar; an in vitro study. J Indian Soc Pedod Prev Dent 2005;23:134-7.

2. Cohen S, Hargreaves KM, Keiser K. Pathways of the pulp. 9th edn. St Louis: Mosby Elsevier, 2006:148-232.

3. Chaudhari P, Mallikarjuna R, Swadas M, Dave B. Unilateral single-rooted primary mandibular first molar. BMJ Case Rep. 2013 Jul 26;2013:bcr2013200034.

4. Ardakani FE, Sheikhha MH, Ahmadi H. Prevalence of dental developmental anomalies: a radiographic study. Community Dent Health. 2007;24(3):140.

5. Saini TS, Kimmes NS, Westerman GH. Aberrant root formation: review of root genesis and three case reports. Pediatr Dent. 2004;26(3):261-5.
6. Ganesh J, Subramanian EMG, Muthu MS. Single-rooted primary first molars. Ind $\mathbf{J}$ Dent Res 2012;23:104-6.

7. Wang J, Feng JQ. Signaling pathways critical for tooth root formation. J Dent Res. 2017;96(11):1221-8.

8. Robbins IM, Keene HJ. Multiple morphologic dental anomalies: report of a case. Oral Surg Oral Med Oral Path Oral Radiol Endod 1964;17:683-90.

9. Ackerman JL, Ackerman AL, Ackerman AB. Taurodont, pyramidal and fused molar roots associated with other anomalies in kindred. Am J Phys Anthrop 1973;38:68194.

10. Holan G, Chosack A. single rooted molars in the primary and permanent dentition in two siblings: Case report. Pediatr Dent 1991;13:367-9.

11. Manoj Kumar MG, Sai Sankar AJ, Srikanth RK. Multiple conical single rooted permenant and primary teeth with oligodontia in 11 year old boy. Ann Essences Dent 2010;2:36-9.

12. Saxena A, Singh A, Ikhar A, Chandak M. A rare case of maxillary first molar with single root and single canal diagnosed using spiral computed tomographic scan. J Indian Soc Pedod Prev Dent. 2014 Jan 7;32(3):242.

13. Gopikrishna V, Bhargavi N, Kandaswamy D. Endodontic management of a maxillary first molar with a single root and a single canal, diagnosed with an aid of spiral CT: A case report. J Endod 2006;32:687-91. 